\title{
O PAPEL DA ARTE NOS CENTROS DE ATENÇÃO PSICOSSOCIAL - CAPS *
}

Claudia Mara de Melo Tavares ${ }^{\star \star}$

Resumo

Estudo sobre o uso da abordagem artística nos cuidados desenvolvidos nos Centros de Atenção Psicossocial (CAPS). Fundamentado em bases conceituais da Reforma Psiquiátrica, o objeto de estudo foi abordado por meio de uma pesquisa exploratória de campo, através da entrevista com profissionais dos CAPS. Os resultados encontrados indicam que atividades de base artística são utilizadas visando a uma interação positiva com o usuário do serviço na perspectiva de sua reabilitação psicossocial. Concluímos que o trabalho no CAPS atualiza a potencialidade criativa dos profissionais e usuários, sendo a arte tomada como uma estratégia de cuidar.

Descritores: terapia pela arte; enfermagem psiquiátrica; prestação de cuidados de saúde; reabilitação; centros de reabilitação

\section{Abstract}

Study about the employment of the artistic approach in the cares developed at the CAPS. Founded on conceptual bases of Psychiatric Reform, the object of study has been broached by means of an exploratory field research through interview with CAPS's professionals. The results found indicate that activities with artistic basis are used by them aiming at a positive interaction with service users, and in the perspective of their psychosocial rehabilitation. We concluded that the work at the CAPS itself brings up-to-date creative potentialities of both professionals and users, being art assumed as an strategy of care.

Descriptors: art therapy; psychiatric nursing; delivery of healthcare; rehabilitation centers; rehabilitation

Title: The role of art in centers of psychosocial care - CAPS
\end{abstract}

\section{Resumen}

Estudio sobre del uso del abordaje artístico y los cuidados desarrollados y los CAPS. Fundamentado en bases conceptuales de la reforma psiquiátrica, el objeto fue abordado en la investigación exploratoria de campo, por medio de entrevistas con profesionales de los CAPS. Los resultados mostraron que la utilización de actividad de base artística tiene en vista la rehabilitación y una positiva interacción con los pacientes. Concluimos que el trabajo en el CAPS actualiza el potencial creativo de los profesionales y pacientes, siendo el arte una estrategia de cuidar.

Descriptores: terapia con arte; enfermería psiquiátrica; prestación de atención de salud Título: El papel de la arte en los centros de atención psicosocial - CAPS

\section{Introdução}

O CAPS como estratégia de cuidar em saúde mental vem sendo utilizado no Brasil desde o final da década de 80 , sendo considerado o dispositivo assistencial prioritário para a substituição dos manicômios. Desde a primeira experiência, CAPS Luiz Cerqueira - Santos, 1988, a idéia de CAPS vem mexendo com o ideário nacional, ampliando os horizontes da clínica para incorporar a dimensão psicossocial. Abandonouse o conceito de doença, passando-se a utilizar o de problemas. Essa nova perspectiva impõe o desenvolvimento de ações voltadas para a promoção da cidadania e inclusão dos doentes mentais. No CAPS, a arte vem sendo utilizada como recurso para as novas terapêuticas implementadas, mas, muitas vezes, a apropriação do seu campo conceitual pelos profissionais de saúde mental ainda ocorre de forma elementar.

O CAPS, no contexto das políticas públicas em saúde mental, surge, não como um modelo assistencial, mas como um projeto que se lança para o futuro, não se cristalizando numa estrutura de saber/poder, mas se constituindo e construindo continuamente a partir das exigências cotidianas dos seus usuários.

De um modo geral, os CAPS atendem a uma clientela de saúde mental considerada grave, tendo o objetivo de manter o cliente em tratamento extra-hospitalar, vinculado à família com perspectiva de retomada das atividades de vida diária, interativas e sociais ${ }^{(1)}$.

Parece claro que a resolução dos problemas em saúde mental requer a conjugação de diferentes interesses. Decisões sobre os caminhos e arranjos a serem seguidos são atribuídos a um conjunto de atores sociais, incluindo profissionais, clientes, familiares e os diferentes organizações engajadas no projeto de ressocialização.
Nos CAPS tem surgido a preocupação com o desenvolvimento de novas tecnologias de cuidar para a resolução de problemas no campo das relações e convivência com a loucura, em substituição à medicalização centrada na expressividade de sintomas.

Nestes serviços o que está em pauta para os profissionais de enfermagem psiquiátrica é a necessidade de construir vínculos, de acolher o sofrimento, de construir uma prática criativa solidária e saber transitar por um conhecimento ecocêntrico, complexo, multidimensional, que privilegie o intercâmbio entre vida e idéias ${ }^{(2)}$

O desafio posto para os profissionais de saúde mental é superar essa histórica fragmentação do saber, partindo para a construção de tecnologias de cuidado que articulem a existência singular do sujeito ao meio (ambiente e social) no qual convive ${ }^{(3)}$. Para isso, há necessidade de compreendermos o contexto mais global e até mesmo ritualístico em que se insere a prática de saúde mental. Uma prática que tem na produção da subjetividade, no imaginário social e na criatividade um dispositivo singular para a criação, promoção de cuidados e qualidade de vida. Uma prática que cria territórios onde o indizível possa ser expresso, onde o invisível possa ser tocado, onde o que chamamos de delírio e alucinação possam ganhar consistência, saindo do plano virtual para o real ${ }^{(4)}$.

Há, historicamente, três grandes tendências para se entender como as alterações mentais são produzidas, a saber: a causa orgânica, a psicológica e a magia. Embora esta última não faça parte da Psiquiatria como campo científico de saber, habita ainda hoje o imaginário social e o senso comum.

Com a evolução da Psiquiatria, instauraram-se como correntes as teorias psicossociais da loucura e as teorias organicistas, contudo ainda existe sobre a doença mental uma aura de magia, ela ainda é vista, como nos mais remotos

* Prêmio Noraci Pedrosa Moreira. 10 lugar. 54 CBEn, 2002.

** Enfermeira. Doutora em Enfermagem. Profa. Titular da Escola de Enfermagem Aurora de Afonso Costa, Universidade Federal Fluminense. Coordenadora do Núcleo de Estudos Imaginário, Criatividade e Cuidado em Saúde - NEICCS.

E-mail do autor: claudianeiccs@aol.com 
tempos, como doença da alma. Esse parentesco da loucura com a magia pode ser positivamente enfrentado pela arte. Pois a arte em sua origem foi magia, foi um auxílio mágico à dominação de um mundo real inexplorado ${ }^{(5)}$

Mas a arte também incita à ação, também é trabalho, é um trabalho mágico que transforma a natureza, para dar-lhe nova forma, novas possibilidades. É necessária para que o homem se torne capaz de conhecer e mudar o mundo ${ }^{(5)}$

A relação da arte com a psiquiatria data do século XIX. No Brasil, esta relação vai ser alimentada, em São Paulo, por Osório César e, no Rio de Janeiro, por Nise da Silveira na década de 30.

A análise dos trabalhos sob o tema - Expressão artística e ato terapêutico - inscritos no I congresso de Saúde Mental do estado do Rio de Janeiro, 1996, demonstra, além do grande interesse desta área temática, uma diversidade de sentidos que a associação arte/terapia alcançou no campo da saúde mental. A partir do discurso presente nos trabalhos evidenciase duas formas de compreender a relação arte/terapia. Uma associa a idéia de arte à de liberdade e a outra ressalta a capacidade da arte de promover integração social, restaurando, assim, a capacidade socializadora do homem ${ }^{(6)}$.

A tendência atual é a utilização da arte como produtora de subjetividade, catalisadora de afetos, engendradora de territórios, embora haja indefinição por parte dos profissionais da área quanto às formas de compreensão da relação arte/ terapia.

São considerados pontos de debate a relação existente entre arte e trabalho, arte e cura, arte e cuidado, arte e humanização da assistência, arte e reabilitação, colocando-se em questão o lugar da arte e da criação no mundo contemporâneo.

Em sua dimensão social a arte possibilita experiências socializadoras e compartilháveis. A arte é tida como meio de produção e inserção social das pessoas portadoras de transtornos mentais ${ }^{(6-10)}$.

A dificuldade básica posta pelo objeto em estudo á a falta de literatura que relacione a arte e a psiquiatria no contexto atual dos CAPS, já que a arte por seu uso nas instituições asilares gerou certa recusa desta abordagem entre os reformadores psiquiátricos. Assim sua relação com a prática de cuidar em saúde mental foi diluída no contexto das oficinas terapêuticas ou das atividades terapêuticas.

A partir dessa contextualização, pergunta-se como se dá a apropriação de atividades de base artística pelos profissionais de saúde mental no cotidiano de cuidar dos usuários dos CAPS ?

Para resposta à questão proposta foi traçado como objetivo: analisar o papel da arte no desenvolvimento do cuidar no CAPS.

Espera-se com este trabalho dar visibilidade ao processo de implementação de atividades de cuidar em saúde mental de base artística, e auxiliar na construção de um modelo criativo de atenção à saúde mental, contribuindo para a análise e avaliação de experiências inovadoras com arte junto aos usuários de CAPS. O estudo possibilitará a apropriação das experiências analisadas por outros serviços de saúde mental evidenciando-se a necessidade de qualificação específica em arte dos profissionais de saúde mental.

\section{Caminhos metodológicos}

Trata-se de uma pesquisa descritiva, exploratória de campo, cuja preocupação central é analisar as práticas terapêuticas e reabilitadoras de base artística utilizadas pelos diversos profissionais de saúde mental no CAPS, com objetivos ligados à teoria, à prática, a eficácia clínica e a formação profissional. O objetivo da investigação centra-se na compreensão dos significados atribuídos pelos profissionais de saúde mental às ações que desenvolvem no CAPS mediados pela arte.

A metodologia desta pesquisa inclui como concepções teóricas de abordagem a multirreferencialidade teórica, com ênfase nos pressupostos da Reforma Psiquiátrica.

Para investigar o que é cuidar com arte nos CAPS, utilizou-se o método de auto-relato, mediante a entrevista estruturada, incluindo perguntas abertas e fechadas.

Utilizou-se a triangulação de dados para analisar dados objetivos e subjetivos, o que permitiu a correção dos "bias" de cada tipo de análise. Através da integração de diferentes dados e modos de análise, as deficiências de um único método podem ser reduzidas ou ultrapassadas, permitindo um realce potencial da validade das descobertas do estudo. A integração de dados qualitativos e quantitativos propicia melhores oportunidades para o teste de interpretação alternativa dos dados, para o exame do quanto o contexto ajudou a moldar os resultados e para a chegada à convergência no exame de um constructo (11).

Em respeito aos aspectos éticos da pesquisa, submeteu-se o projeto de pesquisa ao Comitê de Ética, que emitiu parecer favorável à realização do trabalho. Todos os sujeitos integrantes da amostra foram informados sobre os objetivos da pesquisa e concordaram em participar dela, atendendo-se à Resolução n $196 / 96$ sobre pesquisa envolvendo seres humanos.

Os sujeitos do estudo foram 25 profissionais de saúde mental que atuam nos CAPS de adultos do Município do Rio de Janeiro. Durante a análise dos dados utilizaremos para efeito de identificação das entrevistas, $(P)$ para profissional e $(C)$ para coordenador de CAPS.

Para análise qualitativa dos dados, foi utilizada a técnica de análise temática para identificação das categorias referentes.

\section{Análise e discussão dos resultados}

A arte é reconhecida, desde muito tempo, como a manifestação mais autenticamente libertadora e realizadora da nossa condição humana ${ }^{(5,12-14)}$.

No que tange à implementação de novos dispositivos assistenciais em saúde mental, a arte oferece a possibilidade de reinvenção da existência do doente mental como potência agenciadora de singularidades no processo de construção da cidadania.

A valorização da arte enquanto fonte de inspiração e forma de cuidar não é novidade no campo da saúde mental. Tomando-se por base os dados até aqui apresentados, constatamos serem múltiplas e diversas as referências teóricas sobre o lugar da arte na prática de cuidar nos CAPS. Apesar disso, precisamos considerar que os sentidos atribuídos até o momento não esgotam os sentidos possíveis para a arte.

Os profissionais do CAPS referem que os motivos que os levaram a adotar atividade de base artística no cuidar relaciona-se ao papel ou função da arte por eles percebida: favorecer a comunicação com o paciente; permitir a expressão de emoções e sentimentos; promover a reabilitação; assegurar um espaço de novas experiências para o paciente; possibilitar a construção subjetiva; favorecer a circulação de afetos e de ferramenta terapêutica.

Entre os motivos referidos, ressalta-se a função da arte como mediadora e facilitadora da comunicação com o usuário, conforme exemplificamos nos depoimentos a seguir.

$A$ arte é um instrumento útil para intermediar os contatos pessoais e afetivos entre os usuários (P1).

A arte é um veículo de contato e resgate da história do 
sujeito (P2).

A atividade de base artística é um canal de comunicação e expressão dos usuários do serviço (P6).

A arte ou a atividade de base artística é tida pelos profissionais dos CAPS como um recurso na comunicação com o paciente, confirmando que o fazer artístico proporciona, de forma rápida e eficaz, pontes para a intersubjetividade, para um contato rico, íntimo e profundo, pois ela ajuda à expressão daquilo que mal se vislumbra, que é nebuloso, ou que é complexo e implica uma apreensão simultânea de várias facetas e níveis de significado. Ela permite a expressão de conteúdos que não respeitam a ordenação lógica e temporal da linguagem ${ }^{(15)}$

O campo da saúde mental é o que mais evidencia as alterações no processo de comunicação, sendo consenso entre os profissionais da área que a comunicação é por si só um importante instrumento de intervenção.

Na articulação com a clínica, a comunicação evidenciase como componente central, uma vez que toda tecnologia e processo de cuidar na psiquiatria depende das interações e relações intersubjetivas estabelecidas entre os terapeutas e os usuários (16).

Para ser terapêutica, a comunicação precisa estar voltada para a preservação, a compreensão, o respeito, a cordialidade, a aceitação do paciente ${ }^{(17)}$.

A comunicação terapêutica é descrita como habilidade profissional para ajudar as pessoas a enfrentar seus problemas, a relacionarem-se com os demais, a ajustarem-se ao que não pode ser mudado e a enfrentar os bloqueios à auto-realização (18)

Decifrar e perceber o significado da mensagem que nos é enviada é nossa tarefa como profissionais de saúde mental. Para tanto, precisamos estar atentos aos sinais de comunicação verbal e não verbal emitidos, que transmitem idéias, impressões e imagens de toda ordem. Muitos destes conteúdos, jamais conseguem expressar-se por palavras expressões faciais ou corporais, daí a importância da introdução de objetos, materiais e atividades na comunicação ${ }^{(19)}$.

Assim, a comunicação terapêutica, como um instrumento do cuidar, diminui a ansiedade do sujeito, levandoo a compreender suas limitações e as do meio, passando a adotar formas mais eficazes de interação.

Outro papel apontado para a arte seria o de permitir a expressão de emoções, conforme podemos observar a seguir:

A atividade de base artística é um espaço para expressão, ela melhora a auto-estima do paciente (P4)

$A$ arte é um canal de expressão dos usuários do serviço (P6).

A atividade de base artística é um canal de comunicação e expressão dos usuários do serviço (P6).

A arte é um canal que denuncia conflitos e/ou harmonização das emoções de nossos clientes (P7).

A arte faz parte do ser, é um caminho para a expressão do paciente (C3).

A doença mental parece ser o congelamento da expressão. A loucura deixa o sujeito ancorado num silenciamento. Bloqueado o seu canal de expressão, o sujeito se sente desqualificado para falar e fazer-se compreender. Através da atividade de base artística, o indizível encontra um meio para sua manifestação.

A arte é um processo privilegiado porque possibilita ao sujeito evitar armadilhas, como a das palavras, que são apaziguadoras das emoções, colocando-o num movimento de inventividade no qual pode não só inventar objetos, mas também a vida, o futuro e novas possibilidades existenciais (20)

A expressão consiste em relacionar certos dados atuais ou presentes a objetos ocultos ou distantes, é uma maneira de exteriorizar pensamentos e sentimentos ${ }^{(21)}$. A expressão, assim, é o conjunto de efeitos exteriores da consciência, efeitos que são sintomas de processos interiores ou sinais de estados psíquicos, sentimentos e emotivos.

Há uma preocupação entre os profissionais do CAPS em, de fato, ampliar os meios para escuta do paciente. $E$ a arte parece ser um canal de escuta sensível das emoções e reações subjetivas do paciente, não com o intuito de interpretá-la, como o fizeram os terapeutas decifradores de imagens, mas como possibilidade de reinvenção de suas existências. Outro motivo apresentado é que as experiências artísticas possibilitam a construção subjetiva do paciente:

Compreendo que há uma possibilidade de construção subjetiva, singular através da arte (P10).

Através da arte, podemos construir muitas subjetividades (P14).

Só ao nível do verbal você não consegue retirar o paciente do fechamento. Na oficina, por meio da produção artística, o sujeito pode criar sem ser criticado. Não é o valor estético do seu trabalho que está em jogo, mas a possibilidade de expressão subjetiva (C1).

Entendo que a construção coletiva, à qual se referem os profissionais, está relacionada à linguagem psicanalista, com forte influência nas atividades propostas nos CAPS.

Esta clínica entende o sujeito como um ser aberto a pluralidade das produções que a cultura oferece, aberto a criação de modelos novos de subjetividade, através dos quais os sujeitos se pensam, se sentem, se produzem de forma diferente ${ }^{(22)}$.

Compreende-se que a arte pode possibilitar esta construção por permitir ao sujeito vivenciar outras realidades, conhecer outra forma de ver e imaginar o mundo. Ajudando o sujeito a ser agente de produção de subjetividade e produtor de mecanismos de subjetivação.

A arte no CAPS favorece a troca e a circulação do afeto: $A$ arte funciona como mediadora dos contatos entre os usuários e a equipe técnica e dos usuários entre si, possibilitando o contato afetivo (P3).

Mais importante que a atividade de base artística em si, é a circulação de afetos que ela possibilita (P1).

Entendemos que, com isso, os profissionais estão querendo dizer que, por meio da ação artística no cuidar, profissionais e pacientes se encontram, identificando-se pela sensação que flui da arte, diminuindo, como humanos a sua solidão. Há troca de afetos, só o sujeito afetado pode efetivamente escutar o outro e acolhê-lo.

$\mathrm{O}$ relacionamento afetivo com o profissional leva ao paciente a um contato melhor com o ambiente. A arte catalisa a coordenação das emoções, permitindo a construção de uma síntese, que é a convivência marcada pelo afeto.

A volta à realidade depende, em primeiro lugar, de um relacionamento confiante com alguém, relacionamento que se estenderá aos poucos contatos com outras pessoas e com o ambiente (23)

A arte nos CAPS promove a reabilitação dos portadores de sofrimento psíquico, atribuindo-Ihe a partir de sua produção artística e cultural, valor social de troca e possibilitando-lhe a geração de renda:

A arte atende a necessidade dos usuários acerca da produção. Eles têm necessidade de fazer algo com valor social (P12)

Os usuários estão atrás de um valor comercial para o 
seu produto artístico (P3).

\section{A arte melhora sua auto estima (P4).}

As diversas formas de manifestação artística são relevantes no processo de reabilitação psicossociall (P13).

Gostaria que arte fosse melhor explorada no CAPS que coordeno, infelizmente a equipe daqui parece não se identificar muito com esta linha de trabalho. Acho que a arte possui grande valor como geradora de renda para o paciente (C2).

Quando ele faz alguma coisa nas oficinas que considera bom ou bonito, ele quer logo vender, quer trocar, que mostrar que faz coisa de valor. A arte no CAPS assumiu essa finalidade produtiva e é também um lugar social para o paciente (C3).

A arte possui o papel de promoção artística do paciente e de geração de renda (C4).

Minha motivação na escolha da atividade de base artística como prática de cuidar se deu em função da própria produção escrita dos pacientes, como a poesia, a composição, etc... Existe um interesse do próprio paciente em usar a arte como forma de expressão (P7)

O valor da arte na reabilitação está na possibilidade do paciente, como cidadão, utilizar os aspectos sadios de sua personalidade para conquistar espaços sociais.

A reabilitação psicossocial é um processo de reconstrução do exercício da cidadania e de conquista da contratualidade em três principais cenários: habitat, rede social e trabalho com valor social. A arte por si só não promove a reabilitação, apenas uma etapa de sua construção pode passar por ela, ou pela produção artística ${ }^{(24)}$.

Entende-se que as atividades e as oficinas do CAPS possuem esta finalidade, constituindo-se em uma das etapas necessárias para, destruindo a cronicidade, aumentar a capacidade do paciente estabelecer trocas com a comunidade. Embora menos referida, arte também desempenha no CAPS o papel de ferramenta terapêutica da clínica:

A utilização da arte surge como uma necessidade terapêutica, uma demanda do próprio usuário (P8).

A arte funciona como um veículo de contato e resgate da história do sujeito (P2).

Vejo a arte como expressão e elaboração dos processos terapêuticos (C4).

O paciente que chega ao CAPS, às vezes se sente ameaçado por encontrar tanta gente disponível. Para reabilitá-lo, é preciso colocá-lo em grupo, com materiais artísticos disponíveis, para que ele possa sentir que existe ali, coisas disponíveis e legais ao seu favor e possíveis de serem escolhidas e controladas por ele (C1).

A função terapêutica da arte, que no passado justificava sua apropriação pela psiquiatria, hoje não constitui em seu papel fundamental, outras possibilidades foram apreendidas. O CAPS é mesmo um lugar de reabilitação, não só de pacientes, mas também de profissionais e das técnicas. A mudança de foco, do sintoma para o sujeito, ao meu ver, é que faz toda essa diferença.

Aqui não poderia deixar de mencionar que o papel terapêutico da arte perpassa todos os demais papéis e finalidades, por envolver a utilização, os conhecimentos ou mesmo os fundamentos de base artística nas proposições do cuidar, tenha ele o sentido da clínica ou da reabilitação.

Para os profissionais dos CAPS, a arte deixa de revelar a essência oculta do sujeito, também não se apresenta como um veículo de expressão da verdade interior do indivíduo, seu principal papel, é engendrar novas possibilidades existenciais $^{(6)}$.

A arte no CAPS possui uma função muito mais social do que clínica, sendo a sua função transcendente e estética menos valorizada.

\section{Considerações finais}

A arte é conhecida como um valor pelos profissionais e coordenadores dos CAPS, mas o valor da arte não é explicitado, nem reconhecido como campo de saber científico, pois todos dizem usar essa abordagem sem possuir uma formação correspondente para isso, ou seja, há apropriação empírica ou do senso comum da arte pelos profissionais dos CAPS, até mesmo porque, de fato, o discurso científico não perdeu seu lugar junto às práticas clínicas em saúde mental. Ficou evidenciado que a arte é uma abordagem fundamental do cuidar nos CAPS, assumindo o papel de favorecer a comunicação, de permitir a expressão de emoções, de promover a reabilitação, de assegurar um espaço para novas experiências, para a construção subjetiva, para circulação de afetos e como ferramenta terapêutica. A arte é, portanto, um agenciador de novas possibilidades existenciais para os pacientes e para os profissionais, é um lugar de experimentação, troca de afeto e reabilitação. Não tendo, como no passado, o papel de revelar a essência oculta do sujeito.

Os profissionais de saúde mental buscam realizar no CAPS uma proposta clínica que gere novas possibilidades existenciais para pessoa em sofrimento psíquico e que, ao mesmo tempo, promova a sua valorização social.

As novas formas de cuidar engendradas por esses profissionais são múltiplas, indo desde a percepção de que a oferta de uma roupa limpa e um banho podem melhorar o estado de agitação de um paciente até promover a comercialização das obras produzidas por um paciente.

Entendemos que estas formas de cuidar constituem a arte de cuidar nos CAPS, pois estão fundadas numa visão sensível, emocionada, intuitiva, aberta ao devir e estética da vida.

A relação entre arte e loucura está ligada à necessidade humana de realização, de felicidade, de completitude. A arte nos permite ver mais amplamente o mundo à nossa volta e, ao mesmo tempo, é mergulho na nossa própria intensidade e desejo de realização de nossa diferença. Fazer a diferença ou marcar a diferença parece ser o objetivo de nossa existência, de nossa vida. A arte e a loucura são o fruto dessa suprema lucidez, dessa necessidade de realização, de aceitação, de encontro, de vôo, mergulho e transcendência, mas também de experiência do vazio de sentido, do conflito, do hiato e da dor de estar no mundo.

A arte no CAPS é tomada como atividade meio e não atividade-fim. Ela serve de facilitadora para o alcance de propósitos tidos como "fim" no CAPS, como, por exemplo, a reabilitação psicossocial, ela serve como fonte de inspiração para geração de renda.

O uso da abordagem da arte no CAPS se justifica pela necessidade de fundamentar a prática de cuidar em saúde mental numa perspectiva mais humana, mais criativa, mais preocupada com a qualidade de vida.

\section{Referências}

1. Ribas D, Borenstein M. CAPS - Florianópolis: uma experiência de grupo com clientes psicóticos fora dos muros do manicômio, durante dez anos. Revista Brasileira de Enfermagem, Brasília (DF) 1999 abr/ jun; 52 (2):179-188. 
2. Oliveira F, Silva A. Enfermagem em saúde mental no contexto da reabilitação psicossocial e da interdisciplinaridade. Revista Brasileira de Enfermagem, Brasília (DF) 2000 out/dez 53; (4): 584-592.

3. Tavares CM. A imaginação criadora como perspectiva do cuidar na enfermagem psiquiátrica. [Tese]. Rio de Janeiro: Escola de Enfermagem Anna Nery/UFRJ;1998. 192 f.

4. Guattari F. Caosmose - um novo paradigma estético. Rio de Janeiro: Editora 34;1992.

5. Fischer E. A necessidade da arte. $9^{a}$ ed. Rio de Janeiro: Editora Guanabara; 1987.

6. Leal EML. O agente do cuidado na reforma psiquiátrica brasileira modelos de conhecimento. [Tese]. Rio de Janeiro: Instituto de Psiquiatria/UFRJ;1999.

7. Silveira N. O mundo das imagens. São Paulo: Ática; 1992.

8. Almeida MVM. O estado da arte: uma proposta estética para terapia ocupacional. [Dissertação]. Rio de Janeiro: Escola de Belas Artes/ UFRJ;1997.

9. Vigotski LS. Psicologia da arte. Trad. Paulo Bezerra. São Paulo: Martins Fontes; 1999.

10. Lima EA. A utilização de atividades na clínica da psicose: contribuições da terapia ocupacional. Rev. Perfil 1999; 12: 9-27.

11. Polit $D$, Hungler B. Fundamentos de pesquisa em enfermagem. $3^{\mathrm{a}} \mathrm{ed}$ Porto Alegre: Artes Médicas;1995.

12. Langer S. Sentimento e forma. São Paulo: Perspectiva; 1980

13. Duarte Junior JF. Fundamentos estéticos da educação. São Paulo: Cortez; 1981.

14. Gardner H. As artes e o desenvolvimento humano. Porto Alegre:
Artes Médicas;1994.

15. Ciornai S. Arte-terapia: o resgate da criatividade na vida. In: Carvalho MM, organizadora. A arte cura? São Paulo: Editora Psy II;1995. p.5963.

16. Silva A, Guilherme M, Rocha S, Silva M. Comunicação e enfermagem em saúde mental - reflexões teóricas. Revista Latino-americana de Enfermagem, Ribeirão Preto (SP) 2000 out; 8 (5): p.65-70.

17. Stuart G, Laraia M. Enfermagem psiquiátrica. Rio de Janeiro: Reichmann \& Afonso Ed.;2002.

18. Stefanelli M. Comunicação com o paciente - teoria e ensino. São Paulo: Robe; 1993.

19. Esperidião E. Utilizando sucata na relação terapêutica. Revista Brasileira de Enfermagem, Brasília (DF) 1999 jul/set; 52 (3):469-478.

20. Aquino R. A invenção da vida. Boletim 18 de maio IFB 2002; 9 (22): $7-8$

21. Nunes B. Introdução à filosofia da arte. $5^{\text {a }}$ ed. São Paulo: Ática; 2000.

22. Bezerra B. A clínica e a reabilitação psicossocial. In: Pitta A organizadora. Reabilitação psicossocial no Brasil. $2^{a}$ ed. São Paulo: HUCITEC; 2001. p.137-142.

23. Silveira N. Os inumeráveis estados do ser. Rio de Janeiro: Museu de Imagens do Inconsciente; 1987.

24. Saraceno B. Reabilitação psicossocial: uma estratégia para a passagem do milênio. In: Pitta $A$, organizadora. Reabilitação psicossocial no Brasil. $2^{\mathrm{a}}$ ed. São Paulo: HUCITEC; 2001. p.13-18.

Data de recebimento: 10/11/2002

Data de aprovação: 26/06/2003 